\title{
RANKL IS A NEW EPIGENETIC BIOMARKER FOR THE VASOMOTOR SYMPTOM DURING MENOPAUSE
}

\author{
Kalkan $\mathrm{R}^{1,2,{ }^{*}}$, Altarda $\mathrm{M}^{1}$, Tosun $\mathrm{O}^{3}$ \\ *Corresponding Author: Rasime Kalkan, Ph.D., Department of Medical Genetics, Faculty of Medicine, \\ Near East University, Near East Boulevard, Nicosia, Turkish Republic of Northern Cyprus. \\ E-mail: kalkanr@yahoo.com
}

\begin{abstract}
During menopausal transition, decreased level of estrogen brings a number of physiological problems and hormonal changes. In this study, promoter methylation of RANKL and FSHR genes were identified in 30 premenopausal and 35 postmenopausal women using methylationspecific high resolution melting (MS-HRM) analysis. The statistical analyses and their association with patient characteristics were performed by Pearson $\chi^{2}$ and Fisher's exact test $(p<0.05)$. The methylated RANKL gene was detected in 16 postmenopausal cases, and $12(75.0 \%)$ of the $R A N K L$ methylated cases had hot flashes $(p=0.024)$. The methylated FSHR gene was detected in 18 postmenopausal cases, and $13(75.0 \%)$ of the methylated cases had hot flashes $(p=0.028)$. In vitro studies demonstrated the association between RANKL expression, FSH level and hot flashes in the mouse. Although lack of epigenetic studies in this field proves our results crucial and therefore, our results showed magnitude of epigenetic profiles of Turkish Cypriot postmenopausal women. This was the first study which has investigated the RANKL and FSHR methylation and their relationship with hot flashes in postmenopausal women.

Keywords: Epigenetics; FSHR, RANKL genes; Hot flashes; Menopause.
\end{abstract}

\section{INTRODUCTION}

The first menstrual period and onset of menopause are the key milestones of female reproductive ageing [1].

\footnotetext{
${ }^{1}$ Department of Medical Genetics, Faculty of Medicine, Near East University, Nicosia, Turkish Republic of Northern Cyprus

${ }^{2}$ Experimental Health Sciences Research Center (DESAM), Near East University, Nicosia, Turkish Republic of Northern Cyprus

${ }^{3}$ Department of Biostatistics, Faculty of Medicine, Near East University, Nicosia, Turkish Republic of Northern Cyprus
}

Menopause occurs when the follicle pool in the ovaries has become exhausted and insufficient to maintain menstrual cycles [2]. Genetic and environmental factors are the major determinants of the ending and starting timing of these periods [3].

An increasing number of studies tried to identify the genetic background of reproductive ageing and disorders of reproduction [4-8]. Candidate-gene, genome-wide approach, linkage mapping and association studies tried to highlight genes that are related with the ending time of menstrual cycle. Genome-wide association studies (GWAS) described polymorphic loci in GNRH1, HMCES, ZCCHC27, ZNF518A, NRB2, LY6G5C and BAG69 genes in European [7] and Japanese [9] populations, which was linked with menopause. Day et al. [10] reported the $P T$ PRD, PTPRF, PTPRJ, PTPRK, PTPRS and PTPRZ1 genes to be related to the age of menarche. Epigenetic age is another most popular topic in different types of diseases and recent studies identified statistically significant association with breast cancer susceptibility and increased epigenetic age [10]. Levine et al. [11] used different tissue types to be able to demonstrate the interaction between epigenetic aging and age at menopause. They showed increased epigenetic age in blood samples and this was associated with earlier menopause. The association between single nucleotide polymorphism (SNP), rs11668344 and age of menopause was also identified by Levine et al. [11].

An increasing number of studies tried to identify the genetic background of age of menopause and bone mass differences in menopause. The CYP19A [12], HDC [13], ER $\alpha$ [14-17], FSHR [18] gene polymorphisms are associated with hot flashes and bone mass during the menopause. In addition, until now, the interaction between epigenetics and hot flashes has not been reported in postmenopausal cases.

The RANKL gene is one of the members of the tumor necrosis factor (TNF) family $[19,20]$ and $R A N K L / R A N K$ genes are essential regulators of bone remodeling [21], 
lymph node organogenesis [22] and formation of a lactating mammary gland [23]. These genes are also expressed in the main region of thermoregulation [22] and have an important role for thermoregulation [11]. Hanada et al. [17] tested central RANKL injection in mice and rats and this triggered a severe fever response.

The follicle-stimutating hormone (FSH) is another important hormone in female reproduction which acts via binding to the FSH receptor (FSHR). The interaction between FSHR gene mutations and reproduction in the female has been described by researchers [24-26]. Woad et al. [27] identified mutations that were associated with ovarian dysgenesis (NM 000145.3: c.566C $>$ T) and FSHR function (NM_000145.3: c.1043C $>$ G and NM_000145.3: c. $1555 \mathrm{C}>\mathrm{A}$ ). Sun et al. [28], reported that $\mathrm{FSH}$ is able to directly stimulate osteoclast formation and metabolic activities via its receptor (FSHR). In vitro studies showed that FSHR null mice models demonstrate that FSH is required for postmenopausal bone loss [26-28]. Until now, genetic studies in menopause has been limited and researchers started to analyze a pool of different study populations under a large consortium to increase their power. These studies are based on the assumption of common variants or mutations underlying common bone mineral density, age at menarche and menopause. An increased number of studies in epigenetics helped to identify the genetic background of diseases, such as cancer and aging. In this study, instead of identification of structural genetic variants in menopause, we identified the epigenetic background of the hot flashes in menopause. Here, we reported methylation analysis of FSHR and RANKL genes in patients from Cyprus and identification of an epigenetic background of hot flashes during the menopause.

\section{MATERIALS AND METHODS}

The FSHR and RANKL promoter methylation was analyzed in 35 postmenopausal and 30 premenopausal women. The study was performed in accordance with the Declaration of Helsinki and approved by the Research Ethics Committee of the Near East University, Nicosia, Turkish Republic of Northern Cyprus. Written informed consent was obtained from all subjects participating in the study.

All participants were genetically unrelated postmenopausal females. Subjects with an unnatural menopause, took medications such as anxiolytics, antidepressants, exogenous hormone, women who have serious disease or mental retardation, smoking, alcohol usage and have a weight loss therapy, food allergies, heart disease history, insulin-dependent diabetes, diabetes mellitus type 2 (DMT2), kidney or liver disease, were excluded. Indi- viduals matching the menopause criteria for $>1$ year, were recruited [29].

Genomic DNA was extracted from blood samples according to the AllPrep DNA/RNA/Protein isolation kit (Qiagen $\mathrm{GmbH}$, Hilden, Germany), and its quantity was measured using a NanoDrop ND-1000 Spectrophotometer (Thermo Fisher Scientific, Waltham, MA, USA) at the Near East University Research Center of Experimental Health Sciences (DESAM), Nicosia, Turkish Republic of Northern Cyprus.

Determination of FSHR and $R A N K L$ Methylation Status. To determine the RANKL and FSHR methylation status, first bisulfite modification reaction was applied, and in this reaction, unmethylated cytosine residues were converted to uracil by bisulfite treatment of $1.3 \mu \mathrm{g}$ DNA using the EpiTect Bisulfite Kit (Qiagen $\mathrm{GmbH}$ ) according to the manufacturer's protocol. After conversion, DNA was eluted in buffer (Qiagen $\mathrm{GmbH}$ ) to a final concentration of $30 \mathrm{ng} / \mu \mathrm{L}$. Universal methylated and unmethylated DNA (EpiTect Control DNA Set; Qiagen $\mathrm{GmbH}$ ) were used as methylated and unmethylated controls. We used Rotor Gene Q for methylation-sensitive high resolution melting (MS-HRM) analysis (Qiagen Ltd., Manchester, UK) to detect the methylation status of our samples. Primers were designed according to the EpiTect ${ }^{\circledR}$ HRM $^{\text {TM }}$ PCR (HRMpolymerase chain reaction) Handbook (Qiagen $\mathrm{GmbH}$ ). We used comparable amounts of template genomic DNA for all samples resulting in cycle threshold (CT) values below 30 and differing by no more than three CT values as described previously [29].

Statistical Analyses. The statistical analyses and their associations with patient characteristics were performed by Pearson's $\chi^{2}$ test and two-tailed Fisher's exact test. Calculations were performed using the Statistical Package for the Social Sciences SPSS ${ }^{\circledR} 16.0$ software (SPSS Demo for Mac, Chicago, IL, USA), with a statistical significance of $p<0.05$.

\section{RESULTS}

The mean $( \pm$ SD) age of the 30 premenopause patients was 33.5 years $(33.5 \pm 6.9)$ and for the postmenopause patients $56.7(56.7 \pm 4.9)$.

The $R A N K L$ Methylation and Interactions with Hot Flashes. In the study group: RANKL promoter was methylated in $16(45.7 \%)$ postmenopausal women and 19 $(54.3 \%)$ were unmethylated (Table 1$)$. In $12(75.0 \%)$ of the 16 RANKL methylated postmenopausal cases had hot flashes. There was a statistically significant association identified between two groups $(p=0.024)$ (Table 2).

In the control group, $10(33.3 \%)$ of the samples were methylated and $20(66.7 \%)$ of the samples were unmethyl- 
Table 1. Methylation status of RANKL and FSHR genes in pre- and postmenopausal women.

\begin{tabular}{|l|c|c|c|c|}
\hline Genes & Postmenopause & Premenopause & Positive Hot Flashes History & Negative Hot Flashes History \\
\hline RANKL $(\mathrm{M}) n$ & $16(45.7 \%)$ & $10(33.3 \%)$ & $12(75.0 \%)$ & $4(25.0 \%)$ \\
\hline RANKL $(\mathrm{U}) n$ & $19(54.3 \%)$ & $20(66.7 \%)$ & $7(36.8 \%)$ & $12(63.2 \%)$ \\
\hline FSHR $(\mathrm{M}) n$ & $18(51.4 \%)$ & $20(66.7 \%)$ & $13(72.2 \%)$ & $5(27.8 \%)$ \\
\hline FSHR $(\mathrm{U}) n$ & $17(48.6 \%)$ & $10(33.3 \%)$ & $6(35.3 \%)$ & $11(64.7 \%)$ \\
\hline
\end{tabular}

M: methylated; U: unmethylated.

Table 2. Methylation status of RANKL and FSHR genes and postmenopausal women who have hot flashes.

\begin{tabular}{|l|c|c|c|}
\hline Genes & Positive Hot Flashes History & Negative Hot Flashes History & $p$ Value \\
\hline RANKL $(\mathrm{M}) n$ & $12(75.0 \%)$ & $4(25.0 \%)$ & 0.024 \\
\hline RANKL $(\mathrm{U}) n$ & $7(36.8 \%)$ & $12(63.2 \%)$ & 0.028 \\
\hline FSHR $(\mathrm{M}) n$ & $13(72.2 \%)$ & $5(27.8 \%)$ & \\
\hline FSHR $(\mathrm{U}) n$ & $6(35.3 \%)$ & $11(64.7 \%)$ & \\
\hline
\end{tabular}

M: methylated; U: unmethylated.

ated (Table 1). There was no statistically significant association between menopause and methylation of the RANKL promotor $(p>0.05)$ (Figure 1).

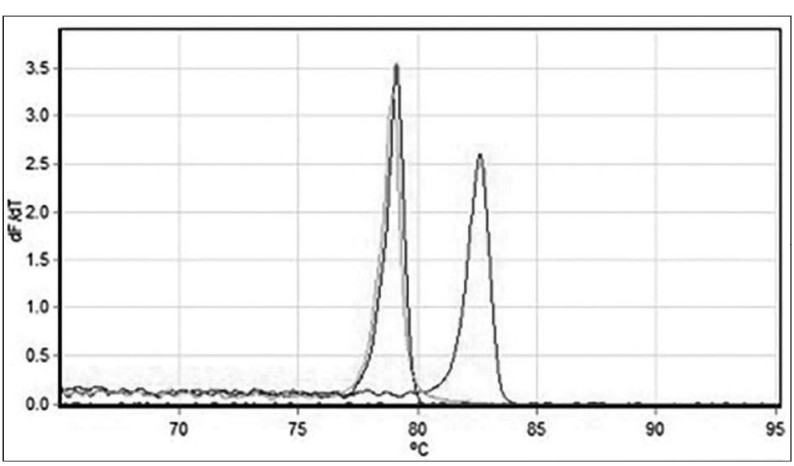

Figure 1. Methylated RANKL patient. The RANKL

unmethylated control is purple, methylated control is red.

Patient \#50 was methylated and patient \#52 was unmethylated.

The FSHR Methylation and Interactions with Hot Flashes. The FSHR gene was methylated in 18 postmenopausal cases and unmethylated in 17 postmenopausal cases. In the control group, FSHR genes were methylated in 20 cases and unmethylated in 10 cases. There was no statistically significant association between two group ( $p$ $>0.05$ ) (Table 2).

Thirteen $(75.0 \%)$ of the 18 FSHR methylated postmenopausal cases had hot flashes. Statistically significant association was identified between the two groups ( $p=$ 0.028) (Table 2).

\section{DISCUSSION}

Several studies focused on identification of interactions between methylation and cancer. Ambatipudi et al.
[2], worked with epigenetic ageing and they showed accelerated epigenetic age was associated with $\mathrm{CpG}$ island methylation and breast cancer susceptibility in postmenopausal women [2]. Epigenetic-based studies in postmenopausal women is limited and the largest part of the studies were related to mutational screening. To the best of our knowledge, this study is the first study which shows the epigenetic alterations in menopause and the epigenetic background of hot flashes in postmenopausal women.

Mutations of the FSHR gene analyzed in different groups, such as premature ovarian failure (POF) [30-37], low number of oocytes [36], age of menopause [37], infertility [38], migraine [39], bone mineral density and bone turnover [18]. Woad et al. [27] searched FSHR variants in exons 7 and 10 in patients who suffered with POF. They identified a novel heterozygous NM_000145.3:c.1411A > T variant in FSHR exon 10 in a family who have a history of POF and elevated FSH concentration [27]. The FSHR mutation and POF interaction has been studied by several researchers [30-34,40].

Rendlina et al. [34] found that the FSHR rs6166 polymorphism significantly influenced bone mineral density (BMD) in postmenopausal women. Cordts et al. [8] concluded that the NM_000145.3: c.919G $>$ A polymorphism in the FSHR gene was associated with premature ovarian insufficiency (POI) development and could be used as a screening marker in patients with ovarian failure [8].

Our study is the first study based on current literature that has shown the interaction between FSHR promoter methylation and hot flashes in postmenopausal patients. The methylated FSHR gene detected in 18 postmenopausal cases and $13(75.0 \%)$ of the methylated cases had hot flashes. There was statistically significant association between the two groups $(p=0.028)$. This was the first study 
which showed the interactions between FSHR methylation and hot flashes in postmenopausal women.

The $R A N K L$ gene is important for bone homeostasis and related biological processes [41]. In fact, the $R A N K L$ gene has been linked as a candidate gene for osteoporosis susceptibility and also confirmed by GWAS, as a susceptibility locus regulating BMD [42]. Single nucleotide polymorphisms of the RANKL promoter showed association with BMD $[41,43,44]$. Mencej et al. [25] showed that promoter polymorphisms of the $R A N K L$ gene was related with elevated transcriptional activity of the gene and correlated with increased RANKL protein rate. This caused imbalances in bone metabolism and was related with low BMD [44]. Shang et al. [40] analyzed SNPs of the $R A N K$ and $R A N K L$ genes in a Chinese female population and showed that the RANKL polymorphisms related with BMD in the femoral neck in peri- and postmenopausal Chinese women [41]. Researchers tried to identify the importance of genetic variations in peri- and postmenopausal women and BMD. The importance of SNPs in BMD has been shown by different researchers $[27,38,45,46]$.

Delgado-Calle et al. [12] showed that increased expression of RANKL during osteoporotic fractures but did not show statistically significant association between methylation and osteoporotic fractures. In vitro studies demonstrated the association between RANKL expression and thermoregulation during postmenopause and also homozygous NM_003701.3: c.508A > G mutation in the $R A N K L$ gene was associated with impaired fever response [47].

Hanada et al. [16] demonstrated that central RANKL injection in mice and rats triggered severe fever and they mapped RANK during the fever response on astrocytes, on the other hand, when they applied high doses of RANKL in the intraperitoneal this did not cause any changes in body temperature or in activity. They highlighted RANKL as an important fever inducer in the central nervous system [16]. Hanada et al. [16] concluded that RANKL/RANK regulates female body temperature and they also demonstrated that ovariectomy-induced changes in core body temperatures occurred in RANK knockout female mice. Hanada et al. $[16,17]$ identified that genetical inactivation of RANK in the brain resulted in an altered physiological thermoregulation in female mice, which, at least in part, appears to be regulated by ovarian sex hormones.

In this study, we detected $R A N K L$ promotor methylation and hot flashes in $12(75.0 \%)$ postmenopausal women $(p=0.024)$ (Table 2). Researchers highlighted that RANKL used a COX2-PGE(2)/EP3R pathway for thermo-regulation and induction of fever. We suggested that increased methylation of RANKL directly effects the expression on the gene and this causes abnormal fluctuation of temperature on postmenopause patients. At the same time, researchers highlighted that deficiency of RANKL/RANK expression is related to osteoporosis and irregular resorption of bone. In accordance with the literature, we can conclude DNA methylation is another mechanism which decreased gene expression and increased irregular resorption of bone but this hypothesis also needs confirmation on bone cells. Here, consistent with the Hanada et al. [16,17] findings, we demonstrated significant association between the RANKL gene methylation and hot flashes in postmenopausal women. On the other hand, we have found significant differences in the gene methylation profiles of the postmenopausal and premenopausal women, including genes that their epigenetic changes have not yet been associated with postmenopausal women. Our findings may provide further insight into the process of postmenopausal changes and gene methylation status. This was the first study that investigated the epigenetic changes of RANKL and FSHR genes in postmenopause and their relation with hot flashes.

Conclusions. In conclusion, we found significant association between the RANKL and FSHR gene methylation and hot flashes in postmenopausal women. Future studies, in larger samples of postmenopausal women, should focus on the study of different gene methylations, and this will help to clarify potential effects of gene methylation in menopause.

\section{ACKNOWLEDGMENTS}

We thank all of the patients for their voluntary support. The authors also thank Dr. Pinar Tulay (Near East University, Nicosia, Turkish Republic of Northern Cyprus) for technical support and for help with DNA extraction.

Declaration of Interest. The authors report no conflicts of interest. The authors alone are responsible for the content and writing of this article.

Funding. This study was supported by the Near East University Scientific Research Project Unit (Nicosia, Turkish Republic of Northern Cyprus) [Grant Number SAG2016-2-012].

\section{REFERENCES}

1. Albagha OME, McGuigan FEA, Reid DM, Ralston SH. Estrogen receptor $\alpha$ gene polymorphisms and bone mineral density: haplotype analysis in women from the United Kingdom. J Bone Miner Res. 2001; 16(1): 128-134.

2. Ambatipudi S, Horvath S, Perrier F, Cuenin C, Hernandez-Vargas H, Le Calvez-Kelm F, et al. DNA methylome analysis identifies accelerated epigenetic 
ageing associated with postmenopausal breast cancer susceptibility. Eur J Cancer. 2017; 75: 299-307.

3. Beau I, Touraine P, Meduri G, Gougeon A, Desroches A, Matuchansky C, et al. A novel phenotype related to partial loss of function mutations of the follicle stimulating hormone receptor. J Clin Invest. 1998; 102(7): 1352-1359.

4. Boyce BF, Xing L. Biology of RANK, RANKL, and osteoprotegerin. Arthritis Res Ther. 2007; 9(Suppl 1): S1.

5. Bucay N, Sarosi I, Dunstan C, Morony S, Tarpley J, Capparelli C, et al. Osteoprotegerin-deficient mice develop early onset osteoporosis and arterial calcification. Genes Dev. 1998; 12(9): 1260-1268.

6. Conway GS, Conway E, Walker C, Hoppner W, Gromoll J, Simoni M. Mutation screening and isoform prevalence of the follicle stimulating hormone receptor gene in women with premature ovarian failure, resistant ovary syndrome and polycystic ovary syndrome. Clin Endocrinol (Oxf). 1999; 51(1): 97-99.

7. Cordero A, Pellegrini P, Sanz-Moreno A, Trinidad EM, Serra-Musach J, Deshpande C, et al. Rankl impairs lactogenic differentiation through inhibition of the pro-lactin/stat5 pathway at midgestation. Stem Cells. 2016; 34(4): 1027-1039.

8. Cordts EB, Santos MC, Bianco B, Barbosa CP, Christofolini DM. Are FSHR polymorphisms risk factors to premature ovarian insufficiency? Gynecol Endocrinol. 2015; 31(8): 663-666.

9. da Fonte Kohek MB, Batista MC, Russell AJ, Vass K, Giacaglia LR, Mendonca BB, et al. No evidence of the inactivating mutation (C566T) in the follicle-stimulating hormone receptor gene in Brazilian women with premature ovarian failure. Fertil Steril. 1998; 70(3); 565-567.

10. Day FR, Thompson DJ, Helgason H, Chasman DI, Fincune H, Sulem P, et al. Genomic analyses identify hundreds of variants associated with age at menarche and support a role for puberty timing in cancer risk. Nat Genet. 2017; 49(6): 1-19.

11. Levine ME, Lu AT, Chen BH, Hernandez DG, Singleton AB, Ferrucci L, et al. Menopause accelerates biological aging. Proc Natl Acad Sci USA. 2017; 113(33): 9327-9332.

12. Delgado-Calle J, Sañudo C, Fernández AF, GarcíaRenedo R, Fraga MF, Riancho JA. Role of DNA methylation in the regulation of the RANKL-OPG system in human bone. Epigenetics. 2012: 7(1): 83-91.

13. Elks CE, Perry JR, Sulem P, Chasman DI, Franceschini $\mathrm{N}, \mathrm{He} \mathrm{C}$, et al. Thirty new loci for age at menarche identified by a meta-analysis of genome- wide association studies. Nat Genet. 2010; 42(12): 1077-1085

14. Falconer H, Andersson E, Aanesen A, Fried G. Follicle-stimulating hormone receptor polymorphisms in a population of infertile women. Acta Obstet Gynecol Scand. 2005; 84(8): 806-811.

15. Guerrini MM, Sobacchi C, Cassani B, Abinun M, Kilic SS, Pangrazio A, et al. Human osteoclast-poor osteopetrosis with hypogammaglobulinemia due to TNFRS F11A (RANK) mutations. Am J Hum Genet. 2008; 83(1): 64-76.

16. Hanada R, Leibbrandt A, Hanada T, Kitaoka S, Furuyashiki T, Fujihara $\mathrm{H}$, et al. Central control of fever and female body temperature by RANKL/RANK. Nature. 2009; 462(7272): 505-509.

17. Hanada R, Penninger JM. Central regulation of body temperature by RANKL/RANK pathway. Clin Calcium. 2011; 21(8): 1201-1208.

18. Hofbauer LC. Osteoprotegerin ligand and osteo-protegerin: Novel implications for osteoclast biology and bone metabolism. Eur J Endocrinol. 1999; 141(3): 195-210.

19. Horikoshi M, Day FR, Akiyama M, Hirata M, Kamatani Y, Matsuda K, et al. Elucidating the genetic architecture of reproductive ageing in the Japanese population. Nat Commun. 2018; 9(1): 1977.

20. Hsu YH, Niu T, Terwedow HA, Xu X, Feng Y, Li $\mathrm{Z}$, et al. Variation in genes involved in the RANKL/ RANK/OPG bone remodeling pathway are associated with bone mineral density at different skeletal sites in men. Hum Genet. 2006; 118(5): 568-577.

21. Kearns AE, Khosla S, Kostenuik PJ. Receptor activator of nuclear factor kappaB ligand and osteoprotegerin regulation of bone remodeling in health and disease. Endocr Rev. 2008; 29(2): 155-192.

22. Kuijper EAM, Blankenstein MA, Luttikhof LJ, Roek SJ, Overbeek A, Hompes PG, et al. Frequency distribution of polymorphisms in the FSH receptor gene in infertility patients of different ethnicity. Reprod Biomed Online. 2010; 20(5): 588-593.

23. Kumar TR. FSH $\beta$ knockout mouse model: A decade ago and into the future. Endocrine. 2009; 36(1): 1-5.

24. Marion S, Oakley RH, Kim KM, Caron MG, Barak LS. A $\beta$-arrestin binding determinant common to the second intracellular loops of rhodopsin family G protein-coupled receptors. J Biol Chem. 2006; 281(5): 2932-2938.

25. Mencej S, Albagha O, Prezelj J, Kocjan T, Marc J. TNFSF11 gene promoter polymorphisms modulate promoter activity and influence bone mineral density 
in post-menopausal women with osteoporosis. J Mol Endocrinol. 2008; 40(6): 273-279.

26. Mitchell ES, Farin FM, Stapleton PL, Tsai JM, Tao EY, Smith-DiJulio K, et al. Association of estrogenrelated polymorphisms with age at menarche, age at final menstrual period, and stages of the menopausal transition. Menopause. 2008; 15(1): 105-111.

27. Woad KJ, Prendergast D, Winship IM, Shelling AN. FSH receptor gene variants are rarely associated with premature ovarian failure. Reprod Biomed Online. 2013; 26(4): 396-399.

28. Sun L, Peng Y, Sharrow AC, Iqbal J, Zhang Z, Papachristou DJ, et al. FSH directly regulates bone mass. Cell. 2006; 125(2): 247-260.

29. Kalkan R, Altarda M, Tulay P, Tosun O. The interaction between ESRRA and PTH gene methylation and body mass index in post-menopausal cases. Cyprus J Med Sci. 2019; 4(3) X-X. doi: 10.5152/ cjms.2019.990.

30. Pérez-Sayáns M, Somoza-Martín JM, Barros-Angueira F, Rey JM, García-García A. RANK/RANKL/ OPG role in distraction osteogenesis. Oral Surg Oral Med Oral Pathol Oral Radiol Endod. 2010; 109(5): 679-686.

31. Perry JRB, Murray A, Day FR, Ong KK. Molecular insights into the aetiology of female reproductive ageing. Nat Rev Endocrinol. 2015; 11(12): 725-734.

32. Perry JR, Stolk L, Franceschini N, Lunetta KL, Zhai G, McArdle PF, et al. Meta-analysis of genome-wide association data identifies two loci influencing age at menarche. Nat Genet. 2009; 41(6): 648-650.

33. Perry JRB, Day F, Elks CE, Sulem P, Thompson DJ, Ferreira T, et al. Parent-of-origin-specific allelic associations among 106 genomic loci for age at menarche. Nature. 2010; 514(7520): 92-97.

34. Rendina D, Gianfrancesco F, De Filippo G, Merlotti D, Esposito T, Mingione A, et al. FSHR gene polymorphisms influence bone mineral density and bone turnover in postmenopausal women. Eur J Endocrinol. 2010; 163(1): 165-172.

35. Rod A, Jarzabek K, Wolczynski S, Benhaim A, Reznik Y, Denoual-Ziad C, et al. ESR1 and FSHR gene polymorphisms influence ovarian response to FSH in poor responder women with normal FSH Levels. Endocrinol Metab Synd. 2014; 3: 3.

36. Sundblad V, Chiauzzi VA, Escobar ME, Dain L, Charreau EH. Screening of FSH receptor gene in Argentine women with premature ovarian failure (POF). Mol Cell Endocrinol. 2004; 222(1-2): 53-59.
37. Zerbetto I, Gromoll J, Luisi S, Reis FM, Nieschlag E, Simoni $\mathrm{M}$, et al. Follicle stimulating hormone receptor and DAZL gene polymorphisms do not affect the age of menopause. Fertil Steril. 2008; 90(6): 2264-2268.

38. Stolk L, Perry JR, Chasman DI, He C, Mangino M, Sulem P, et al. Meta-analyses identify 13 loci associated with age at menopause and highlight DNA repair and immune pathways. Nat Genet. 2012; 44(3): 260-268.

39. Coşkun S, Yücel Y, Çim A, Cengiz B, Oztuzcu S, Varol S, et al. Contribution of polymorphisms in ESR1, ESR2, FSHR, CYP19A1, SHBG, and NRIP1 genes to migraine susceptibility in Turkish population. $\mathrm{J}$ Genet. 2016; 95(1): 131-140.

40. Shang M, Lin L, Cui H. Association of genetic polymorphisms of RANK, RANKL and OPG with bone mineral density in Chinese peri- and postmenopausal women. Clin Biochem. 2013; 46(15): 1493-1501.

41. Tu P, Duan P, Zhang RS, Xu DB, Wang Y, Wu HP, et al. Polymorphisms in genes in the RANKL/RANK/ OPG pathway are associated with bone mineral density at different skeletal sites in post-menopausal women. Osteoporos Int. 2015; 26(1): 179-185.

42. Sowers M, Willing M, Burns T, Deschenes S, Hollis $\mathrm{B}$, Crutchfield $\mathrm{M}$, et al. Genetic markers, bone mineral density, and serum osteocalcin levels. J Bone Miner Res. 2009; 14(8): 1411-1419.

43. Wang J, Wang Y, Zhao Y, Li Y, Sun M, Na R, et al. Polymorphisms of genes in the OPG/RANKL/RANK pathway in the Mongols of Inner Mongolia China: Relationship to other populations. Int J Clin Exp Med. 2016; 9(2): 3851-3859.

44. Willing M, Sowers M, Aron D, Clark MK, Burns T, Bunten $\mathrm{C}$, et al. Bone mineral density and its change in White women: Estrogen and vitamin D receptor genotypes and their interaction. J Bone Miner Res. 2009; 13(4): 695-705.

45. Voorhuis M, Onland-Moret NC, van der Schouw YT, Fauser BC, Broekmans FJ. Human studies on genetics of the age at natural menopause: A systematic review. Hum Reprod Update. 2010; 16(4): 364-377.

46. Zaidi M, Blair HC, Iqbal J, Zhu LL, Kumar TR, Zallone A, et al. Proresorptive actions of FSH and bone loss. Ann NY Acad Sci. 2007; 1116: 376-382.

47. Zheng H, Wang C, Wei H, Fu WZ, Zhang ZL. OPG, RANKL, and RANK gene polymorphisms and the bone mineral density response to alendronate therapy in postmenopausal Chinese women with osteoporosis or osteopenia. Pharmacogenet Genomics. 2016; 26(1): 12-19. 